\title{
The response during a pandemic is a blurred vision of the future. Reflections on the Lombardy reorganization of the neurosurgical emergencies during the COVID-19
}

\author{
Carlo Giussani $^{1,2} \cdot$ Erik Sganzerla $^{1,2} \cdot$ Luca Valvassori $^{3} \cdot$ Mario Alparone $^{4} \cdot$ Giuseppe Citerio $^{1,5}$
}

Received: 3 April 2020 / Accepted: 4 April 2020 / Published online: 21 April 2020

(C) Springer-Verlag GmbH Austria, part of Springer Nature 2020

\section{Dear Editor,}

We read with interest the editorial of Zoia and colleagues about the reorganization of neurosurgical activities, both elective and urgent, to face the COVID-19 outbreak and the viewpoint summarizing the actual situation. However, as neurosurgeons, neuroradiologists, and neurointensivists working in a regional tertiary referral hospital for TBI and ischemic/ hemorrhagic strokes (in this period redefined as a hub center for stroke and COVID-19 and as spoke center for neurosurgery), we would like to highlight the weakness of the presented scenario on the long run.

The authors specified that three neurosurgical hubs have been defined on geographical bases, covering roughly $1 / 3$ of Lombardy territory (10.4 million inhabitants, $23,861 \mathrm{~km}^{2}$ ) each. This redistribution is aimed to distribute time-dependent neurosurgical emergencies in hospitals with "almost" COVID-free dedicated pathways and facilities. This produced a downgrade of hospitals with a high volume of neurosurgical and neurological emergencies. High volume is an important characteristic of a hub, along with the served territory (in our case covering also

This article is part of the Topical Collection on Neurosurgery general

Carlo Giussani

carlo.giussani@unimib.it

1 School of Medicine and Surgery, Università degli Studi di Milano Bicocca, Milano, Italy

2 Neurosurgery, Ospedale San Gerardo, Azienda Socio Sanitaria Territoriale di Monza, via G.B. Pergolesi 33, 20900 Monza, MB, Italy

3 Neuroradiology, Ospedale San Gerardo, Azienda Socio Sanitaria Territoriale di Monza, Monza, Italy

4 General Manager Department, Azienda Socio-Sanitaria Territoriale di Monza, Ospedale San Gerardo, Monza, Italy

5 Neurointensive Care Unit, Ospedale San Gerardo, Azienda Socio Sanitaria Territoriale di Monza, Monza, Italy remote mountains location for strokes) [1, 3]. Moreover, hubs should have teaching facilities as university-affiliated hospitals and/or could participate in international trials on trauma and cerebrovascular disease, both pharmacological and government/EU-funded research [1-3]. Research and teaching are among the criteria that can reflect the top-notch characteristics of an institution and a clinical group.

As stated by the colleagues, the reorganization of the system forced by a pandemic is sustainable in the short, emergent period because "the public 'lockdown' has tangibly diminished the number of traumatic cases" and we concurrently observed a reduction of all the neurosurgical/neurological emergency admissions. At the same time, we completely agree with the colleagues when they state that "in difficult times such as these, the cooperative spirit has risen spontaneously to previously unmet levels." The unexpected readiness of neurosurgeons to convert to COVID-19 doctors and the acceptance of centralizing in dedicated structures the majority of the time-dependent neurosurgical activities requiring postoperative intensive care, with teams moving between hospitals, are testimony of it.

However, in our opinion, we do not think that the reorganized system is "hopefully creating the basis for an interesting new standard for the post-COVID-19 period." We are sure that with the return (hopefully soon) to normality, the current model would not be enough to face all the needs of the region as demonstrated until February 21, 2020.

We are convinced that the emergency system needs a reevaluation and adaptation at the end of the crisis. For sure, the system will be different afterwards, more efficient, but the snapshot during the pandemic, described by Zoia, is only a blurred vision of the future.

In the post-COVID-19 period, a reduction of the hubs for neurosurgical emergency, probably hypertrophic before the pandemic, is desirable but the correct identification of them, not only based on geographical criteria or political considerations, should be integrated by an evaluation that considers: 
1. An ideal ratio of neurosurgery unit/million inhabitants suitable to the demographic, geographic, and road/air transportation features of our Region

2. The volume of activities before the pandemic

3. The availability $24 / 24$ of facilities and expertise like neuroICUs and interventional neuroradiologists

4. The participation in international clinical research

5. The possibility to deliver teaching activities to medical students and residents

6. The availability of ancillary expertise such as maxillofacial surgery and/or ENT surgery

In conclusion, as Peter Abelard (1079-1142) (Sic et Non, Prologus) wrote "Prima sapientiae clavis definitur, assidua scilicet seu frequens interrogatio...Dubitando enim ad inquisitionem venimus; inquirendo veritatem percipimus." (translation: "Constant and frequent questioning is the first key to wisdom ... For through doubting we are led to inquire, and by inquiry, we perceive the truth").

\section{References}

1. Davies JM, Ozpinar A, Lawton MT (2015) Volume-outcome relationships in neurosurgery. Neurosurg Clin N Am 26(2):207-218

2. Steyerberg EW, Wiegers E, Sewalt C et al (2019) Case-mix, care pathways, and outcomes in patients with traumatic brain injury in CENTER-TBI: a European prospective, multicentre, longitudinal, cohort study. Lancet Neurol 18(10):923-934

3. Yoon JS, Tang OY, Lawton MT (2019) Volume-cost relationship in neurosurgery: analysis of 12,129,029 admissions from the National Inpatient Sample. World Neurosurg 129:e791-e802

Publisher's note Springer Nature remains neutral with regard to jurisdictional claims in published maps and institutional affiliations. 